\title{
Aversive olfactory learning and associative long-term memory in Caenorhabditis elegans
}

\author{
Hisayuki Amano and Ichiro N. Maruyama ${ }^{1}$ \\ Information Processing Biology Unit, Okinawa Institute of Science and Technology, Okinawa 904-0412, Japan
}

\begin{abstract}
The nematode Caenorhabditis elegans ( $C$. elegans) adult hermaphrodite has 302 invariant neurons and is suited for cellular and molecular studies on complex behaviors including learning and memory. Here, we have developed protocols for classical conditioning of worms with 1-propanol, as a conditioned stimulus (CS), and hydrochloride ( $\mathrm{HCl})(\mathrm{pH} 4.0)$, as an unconditioned stimulus (US). Before the conditioning, worms were attracted to 1-propanol and avoided $\mathrm{HCl}$ in chemotaxis assay. In contrast, after massed or spaced training, worms were either not attracted at all to or repelled from 1-propanol on the assay plate. The memory after the spaced training was retained for $24 \mathrm{~h}$, while the memory after the massed training was no longer observable within $3 \mathrm{~h}$. Worms pretreated with transcription and translation inhibitors failed to form the memory by the spaced training, whereas the memory after the massed training was not significantly affected by the inhibitors and was sensitive to cold-shock anesthesia. Therefore, the memories after the spaced and massed trainings can be classified as long-term memory (LTM) and short-term/middle-term memory (STM/MTM), respectively. Consistently, like other organisms including Aplysia, Drosophila, and mice, $C$. elegans mutants defective in nmr-1 encoding an NMDA receptor subunit failed to form both LTM and STM/MTM, while mutations in crh-1 encoding the CREB transcription factor affected only the LTM.
\end{abstract}

[Supplemental material is available for this article.]

The major advantage of invertebrate systems for the study of learning and memory is the relative simplicity of their nervous systems. Furthermore, invertebrate nervous systems consist of so-called identified neurons whose size, position, electrical properties, basic synaptic connections, and physiological and behavioral functions are more or less invariant from animal to animal of a given species (Kandel 1976). In associative learning, particularly classical conditioning, animals learn to associate a conditioned stimulus (CS) with an unconditioned stimulus (US). Memory can last in various phases from as short as seconds, as is found in short-term memory (STM), or as long as hours to a lifetime, as is found in long-term memory (LTM). Between STM and LTM in Drosophila, amnesiac-dependent anesthesia-sensitive middleterm memory (MTM) exists for several hours (Tully and Quinn 1985; Folkers et al. 1993). The cellular and molecular mechanisms behind these phases of memory seem to be distinct (DeZazzo and Tully 1995; Hammer and Menzel 1995). For example, LTM, but not STM, can be disrupted by treatments such as electroconvulsive shock or inhibitors of protein synthesis (Davis and Squire 1984). Memory processing, storage, and retrieval are each remarkably dynamic, and one of the hallmarks of memory is a progressive consolidation from initially labile STM, which is short lived and vulnerable to disruption such as anesthesia, into LTM, which is highly resistant both to experimental manipulation and to the passage of time.

Typically, STM/MTM is induced by massed training, and LTM by spaced training. Spaced training consists of repeated training sessions with an intertrial interval (ITI) (also called "a resting interval") and generates memory dependent on mRNA and protein synthesis, and massed training comprises repeated trials without an ITI and induces memory independent of mRNA and

\footnotetext{
${ }^{1}$ Corresponding author.

E-mail ichi@oist.jp.

Article is online at http://www.learnmem.org/cgi/doi/10.1101/Im.2224411.
}

protein synthesis (Tully et al. 1994; Beck and Rankin 1995; Crow et al. 1997; Epstein et al. 2003; Fulton et al. 2005). The augmentation in memory induced by spaced training is called the spacing effect and is a common phenomenon in the animal kingdom, including humans (Carew et al. 1972; Tully et al. 1994; Gerber et al. 1998; Beck et al. 2000; Rose et al. 2002; Cepeda et al. 2006). An interstimulus interval (ISI) is also a crucial parameter affecting the outcome of classical conditioning in intact animal studies. In general, when presentation of a CS precedes that of a US by a brief interval, optimal conditioning is observed. For this "forward conditioning," studies of CS-US interval effects typically show an asymmetric, inverted U-shaped gradient relating the magnitude of conditioning to the ISI (Jones 1962; Schneiderman and Gormezano 1964, Hawkins et al. 1986). In contrast, successful "backward conditioning," in which presentation of a US precedes that of a CS, has also been observed less frequently (Dostalek 1976; Spetch et al. 1981; Durkovic and Damianopoulos 1986).

C. elegans detects various environmental cues such as odorants and tastants mainly through its amphid sensilla. The amphids are the largest chemosensory organs, and each amphid consists of 12 sensory neurons with ciliated dendrites, as well as one sheath and one socket cell (Ward et al. 1975; Ware et al. 1975). These amphid neurons have roles in chemotaxis, thermotaxis, mechanosensation, osmotaxis, and dauer pheromone sensation (Bargmann and Mori 1997; Driscoll and Kaplan 1997; Riddle and Albert 1997; de Bono and Maricq 2005; Bargmann 2006). Chemotaxis of $C$. elegans to cations, anions, cyclic nucleotides, and amino acids was first described by Ward (1973), and since then this list has been extended further and includes many olfactory stimuli (Bargmann et al. 1993). The sensory neurons required for chemosensory responses have been identified by laser microsurgery of identified neurons (Bargmann and Horvitz 1991). In addition, the wiring diagrams of all neurons have been reconstructed from electron micrographs of serial thin sections of the entire C. elegans body (White et al. 1986). 
C. elegans can learn a variety of nonassociative and associative tasks (Ishihara et al. 2002; Mohri et al. 2005; Torayama et al. 2007; Ardiel and Rankin 2010). Mechanosensory habituation as nonassociative learning is one of the most studied learning paradigms in C. elegans (Rankin et al. 1990; Rankin and Broster 1992; Rose et al. 2002; Rose and Rankin 2006). Associative learning in C. elegans has first been suggested from the finding that worms return to their temperature of cultivation if they had food at that temperature (Hedgecock and Russell 1975). Most of associative learning paradigms in C. elegans are based on pairing chemical cues or cultivation temperature with food or starvation. Conditioning worms with sodium chloride in the absence of food leads to a significant reduction in chemotaxis compared with conditioning in the presence of food (Wen et al. 1997; Saeki et al. 2001; Tomioka et al. 2006). Similar observations have been made in olfactory paradigms (Colbert and Bargmann 1997; Morrison et al. 1999; Nuttley et al. 2002). C. elegans can also learn to avoid odors associated with infection by pathogenic bacteria, a behavior analogous to mammalian conditioned taste aversion (Zhang et al. 2005). Mutant screens for worms defective in learning have resulted in the identification of $l r n-1$ and $l r n-2$, which affect both taste learning and olfactory learning (Wen et al. 1997; Morrison et al. 1999). Therefore, screens based on these complex behaviors should be useful in the identification of many new genes.

In some cases, the $C$. elegans learning paradigms meet strict criteria for associative learning set forth in the psychology literature (Rankin 2000). More often, however, C. elegans learning paradigms have a mixed character in which the distinction between associative learning and nonassociative sensitization, habituation, and adaptation is not clear, particularly when pairing chemical cues or cultivation temperature with food or starvation (Bargmann 2006). This is partly because C. elegans behaviors are dramatically affected by the presence and absence of food (Gray et al. 2005). Rather than pairing chemical cues with food or starvation, therefore, it would be preferable for subsequent analysis of neuronal circuits responsible for associative learning and memory that two defined chemical cues are used for conditioning of worms. Indeed, diacetyl and acetic acid were successfully used as CS and US, respectively, to induce olfactory associative memory in C. elegans, although it was not shown whether the memory formation is dependent on protein synthesis or not (Morrison et al. 1999; Morrison and van der Kooy 2001).

In the present study we have developed a protocol for the study of aversive olfactory learning and associative LTM in C. elegans. In this paradigm, we conditioned worms with 1-propanol as a CS, and hydrochloric acid $(\mathrm{HCl})$ as a US. Spaced training of worms with 1-propanol and $\mathrm{HCl}$ induced LTM, while massed training induced STM/MTM, which was disrupted by cold-shock anesthesia. The formation of the LTM, but not the STM/MTM, is dependent on mRNA and protein syntheses. Moreover, it has also been found that several C. elegans mutants are defective in the LTM formation.

\section{Results}

\section{Aversive classical conditioning of worms with propanol and acidic $\mathrm{pH}$}

An olfactory cue, 1-propanol, is an attractant for C. elegans (Fig. 1; Bargmann et al. 1993), while worms are repelled from acidic $\mathrm{pH}$ lower than pH 4.0 (Sambongi et al. 2000; Supplemental Fig. S1). Utilizing 1-propanol and acidic $\mathrm{pH}$ as a CS and a US, respectively, we developed classical conditioning protocols for the study of associative learning in C. elegans. Worms repeatedly conditioned with deionized $\mathrm{H}_{2} \mathrm{O}\left(\mathrm{dH}_{2} \mathrm{O}\right), \mathrm{HCl}(\mathrm{pH} 4.0)$, or $1.0 \%$
A

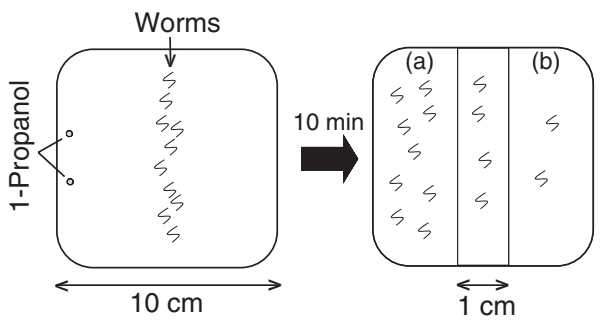

Chemotaxis Index $(\mathrm{Cl})=(\# \mathrm{a}-\# \mathrm{~b}) /(\# \mathrm{a}+\# \mathrm{~b})$

B Spaced training:

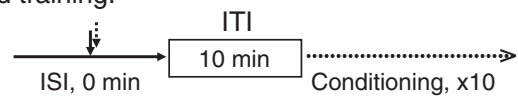

Massed training: $\frac{\text { Conditioning, } \mathrm{x} 10}{\mathrm{M}}$

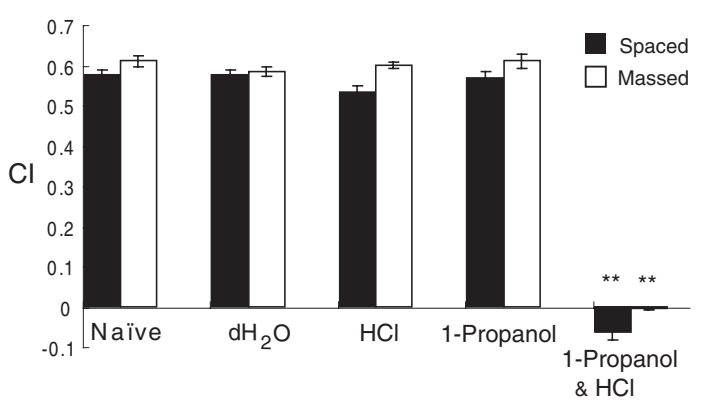

Learning Index $(\mathrm{LI})=\mathrm{Cl}_{\text {reference }}-\mathrm{Cl}_{\text {conditioned }}$

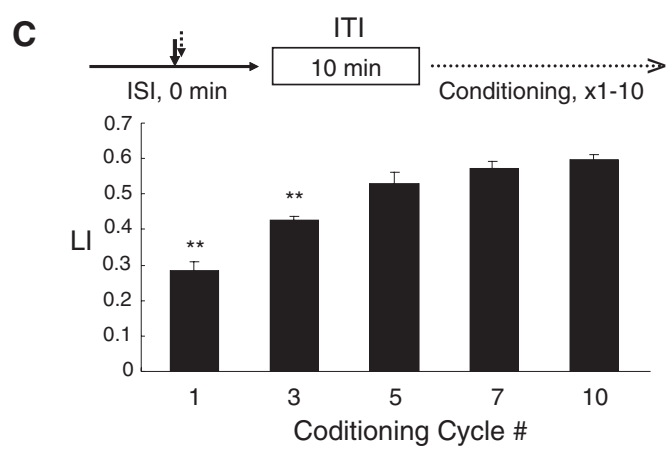

Figure 1. Chemotaxis assay and classical conditioning of $C$. elegans. $(A)$ Schematic representation of chemotaxis assay of worms to 1-propanol, which was carried out on square agar plates as described in the Materials and Methods. Worms were allowed to move freely on the agar for $10 \mathrm{~min}$ at room temperature. Chemotaxis index $(\mathrm{Cl})$ values were calculated from the equation shown. $(B) \mathrm{Cl}$ values of worms to 1-propanol after spaced or massed training with chemicals indicated. Flowcharts of the spaced and massed training protocols used are shown at top. $\mathrm{LI}$ values were calculated by using the equation shown. The $\mathrm{Cl}$ value of reference worms $\left(\mathrm{Cl}_{\text {reference }}\right)$ was the mean value of $\mathrm{Cl}$ values of worms conditioned with $\mathrm{HCl}$ alone and 1-propanol alone. Bars are means \pm SEM ( $n=9$ assays). Asterisks indicate statistically significant differences $(* * P<0.01)$ determined by one-way ANOVA with the Bonferroni/Dunn test, in comparison to the $\mathrm{Cl}$ of naive worms. (C) $\mathrm{LI}$ values of worms repeatedly conditioned as indicated on the horizontal axis. At each cycle of the trials, worms were simultaneously conditioned with a solution containing 1.0\% 1-propanol and $100 \mu \mathrm{M} \mathrm{HCl}(\mathrm{pH} 4.0)$ with a 10-min ITI. Bars are means $\pm \operatorname{SEM~(~} n=9$ assays). Asterisks indicate statistically significant differences $(* * P<0.01)$ determined by one-way ANOVA with Bonferroni/Dunn test, in comparison to the $\mathrm{LI}$ of worms trained with 10 conditioning cycles. 
aqueous 1-propanol by spaced (with a 10-min ITI) or massed (without an ITI) training were as sensitive to 1-propanol as naive worms and were indistinguishably attracted to 1-propanol from naive worms in the chemotaxis assay (Fig. 1B; Supplemental Fig. S2). In contrast, worms conditioned with both 1-propanol and $\mathrm{HCl}$ by spaced or massed training avoided 1-propanol or were not attracted at all by 1-propanol, respectively (Fig. 1B). Learning index (LI) was calculated by subtracting the chemotaxis index (CI) (Fig. 1A) of conditioned worms with both 1-propanol and $\mathrm{HCl}$ from the CI of reference worms, which was the mean of CI values of worms conditioned with $\mathrm{HCl}$ alone and 1-propanol alone (Fig. 1B). When worms were conditioned repeatedly with (spaced training) or without (massed training) ITI by soaking them briefly $(<1.0 \mathrm{sec})$ in a solution containing both 1-propanol and $\mathrm{HCl}$, LI values of the trained worms were elevated and reached a plateau (Fig. 1C) as the cycle number of the trials was increased up to 10 times.

\section{Optimal ISI and ITI lengths for memory acquisition and retention}

To optimize the conditioning protocols, we examined the effect of an ISI on memory acquisition and retention. The ISI is a period of time between two stimulations of worms with CS and US. Figure 2A shows conditioning protocols for "backward conditioning," in which worms were stimulated with $\mathrm{HCl}$ before 1-propanol stimulation, "simultaneous conditioning," in which worms were stimulated with a solution containing both 1-propanol and $\mathrm{HCl}$, and "forward conditioning," in which worms were stimulated with $\mathrm{HCl}$ after 1-propanol stimulation. The conditioning protocols with various lengths of ISI were repeated five times with a 10-min ITI.

Of ISI lengths tested, the simultaneous conditioning was the best for both memory acquisition and 3-h retention. LI values of worms conditioned with the CS or US immediately (a 0-min ISI) after US or CS, respectively, were statistically indistinguishable from those of worms simultaneously conditioned with a solution containing both 1-propanol and HCl. However, LI values measured immediately or $3 \mathrm{~h}$ after the final trial of the conditioning were decreased with longer ISI lengths in both of the forward and backward conditionings. When an ISI between the CS and US was longer than $2 \mathrm{~min}$, both of the forward and backward conditionings failed to induce the memory. Thus, the simultaneous conditioning is most efficient for inducing the associative memory of two stimuli, 1-propanol and $\mathrm{HCl}$.

As shown above in Figure 1C, multiple trials of the conditioning enhanced the LI. Studies of other organisms have shown that an ITI between conditioning trials is a crucial factor in the efficacy of memory formation, memory retention in particular (Yin et al. 1994; Carew 1996). Therefore, we also examined the effect of ITI lengths on the memory acquisition and retention. Worms were given five trains of the conditioning, of which ITI lengths ranged from $0 \mathrm{~min}$ through $30 \mathrm{~min}$. The memory acquisition and retention were analyzed by measuring the LI values immediately and $3 \mathrm{~h}$, respectively, after the trainings with various ITI lengths (Fig. 2B). Five trial sessions with no ITI (massed training) induced memory statistically indistinguishable from that induced by the spaced training with ITIs when assayed with the LI immediately after the trainings. However, the conditioned response was no longer observed beyond $3 \mathrm{~h}$. In contrast, when assayed $3 \mathrm{~h}$ after the training, the LI of worms conditioned by the spaced training was elevated as the ITI length was increased up to $10 \mathrm{~min}$, and then the LI was gradually decreased when ITIs were longer than $10 \mathrm{~min}$. These results demonstrate that the 10-min ITI is most efficient for worms to retain the memory for $3 \mathrm{~h}$ after the training. For subsequent experiments, therefore, we conditioned worms
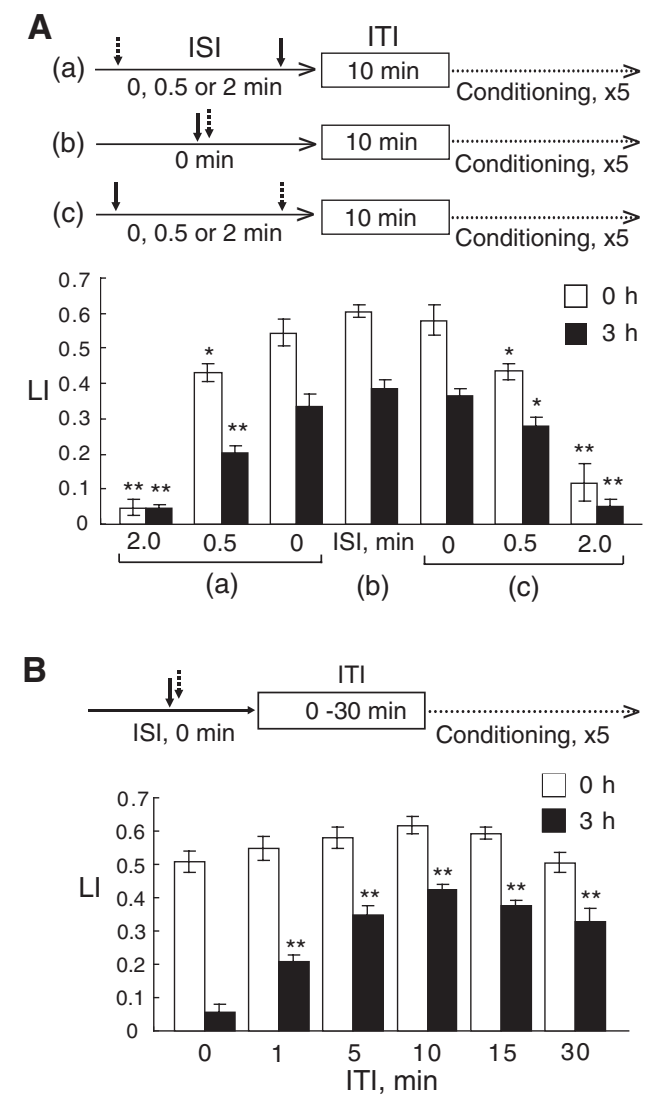

Figure 2. Effects of ISI and ITI lengths on memory acquisition and retention. $(A)$ Effects of ISI lengths on memory acquisition and retention. Flowcharts of backward (a), simultaneous (b), and forward (c) conditioning protocols used are shown at top. In the backward conditioning (a), worms were first stimulated with $\mathrm{HCl}$ as a US (dotted arrow), and then with 1-propanol as a CS (solid arrow) for $0 \mathrm{~min}, 0.5 \mathrm{~min}$, or $2 \mathrm{~min}$ after the US stimulation. In the simultaneous conditioning (b), worms were soaked in a solution containing both 1-propanol and $\mathrm{HCl}$. In the forward conditioning (c), worms were first stimulated with 1-propanol and then with $\mathrm{HCl}$ for $0 \mathrm{~min}, 0.5 \mathrm{~min}$, and $2 \mathrm{~min}$ after the CS stimulation. These procedures were repeated five times with a 10-min ITI, and then worms were examined for their LI immediately (open bars) and $3 \mathrm{~h}$ (closed bars) after the completion of the repetitive conditionings. Data are means \pm SEM ( $n=10$ assays). Asterisks indicate statistically significant differences $\left({ }^{*} P<0.05 ;{ }^{* *} P<0.01\right)$ determined by one-way ANOVA with Bonferroni/Dunn test, in comparison to the LI of worms simultaneously conditioned in b. (B) Effects of ITI lengths on memory acquisition and retention. A flowchart of the conditioning used is shown at top. Worms were simultaneously stimulated by being soaked in a solution containing both 1-propanol and $\mathrm{HCl}$, followed by various ITI lengths ranging from $0 \mathrm{~min}$ through $30 \mathrm{~min}$. These conditioning procedures were repeated five times, and then the worms were tested for $\mathrm{LI}$ values immediately (open bars) or $3 \mathrm{~h}$ (closed bars) after the completion of the repetitive conditionings. Data are means $\pm \operatorname{SEM}(n=9$ assays). Asterisks indicate statistically significant differences $\left({ }^{* *} P<0.01\right)$ determined by one-way ANOVA with Bonferroni/Dunn test, in comparison to the LI of worms conditioned without an ITI.

by repeating the trial 10 times with or without a 10-min ITI as spaced or massed conditioning, respectively.

\section{Memory retention and extinction}

With optimized ISI and ITI lengths as well as with optimal trial numbers of the conditioning, we also measured the period of time (retention time) that the memory induced by the massed or spaced training was retained. Well-fed worms were conditioned 10 times by massed or spaced training with a solution containing 
both 1-propanol and $\mathrm{HCl}$, and then the worms were transferred to NGM plates with a bacterial lawn, where they were allowed to move and eat at $20^{\circ} \mathrm{C}$ during retention intervals. Figure $3 \mathrm{~A}$ shows various retention times of the memory induced by the massed or spaced training. Memory acquisition after the massed and spaced training was similar to each other. However, memory induced by the massed training was no longer observable within $3 \mathrm{~h}$, as also shown above in Figure 2B (a 0 -min ITI). In contrast, memory induced by the spaced training was retained for up to $24 \mathrm{~h}$.

Furthermore, when the worms conditioned by the spaced training were repeatedly exposed to the CS in the absence of the US, their LI values were progressively decreased (Fig. 3B), suggesting that extinction learning can also occur in the simple C. elegans nervous system. During the extinction, the conditioned worms showed a statistically significant decrease in LI values, compared with worms treated with $\mathrm{dH}_{2} \mathrm{O}$ as a negative control in the same way as that with the CS alone. This decrease is not due to habituation or adaptation, since chemotactic activity of the worms exposed repeatedly to the CS alone is similar to that of the control worms treated with $\mathrm{dH}_{2} \mathrm{O}$ (Supplemental Fig. S3). Under the experimental conditions for the extinction learning, the decrease in LI values was not complete even after 10 -cycle extinction training trials as observed in other organisms such as Aplysia (Carew et al. 1981) and Drosophila (Qin and Dubnau 2010).

\section{Propanol-specific associative learning}

We then asked whether or not the STM/MTM and LTM formations were specific for 1-propanol. Worms conditioned simultaneously 10 times with 1-propanol and $\mathrm{HCl}$ by the massed or spaced training were tested for their chemotaxis to benzaldehyde, isoamyl alcohol, and diacetyl (Fig. 4A), and their LI values were calculated from their CI values. The concentrations of the stimuli in the chemotaxis assay were adjusted based on the CI values of naive worms to the stimuli. As shown in Figure 4B, the worms conditioned with 1-propanol and $\mathrm{HCl}$ could learn 1-propanol as a specific stimulus, since they could not associate the US with benzaldehyde, isoamyl alcohol, or diacetyl. These stimuli are sensed by AWA or AWC olfactory sensory neurons (Bargmann et al. 1993), which are responsible for the detection of most, if not all of the attractive olfactory cues. Therefore, it is likely that 1 -propanol is also sensed by one of these neurons, suggesting that two different stimuli sensed by the same sensory neuron can induce memory in different ways, probably through different neural circuits, from each other.

\section{Effect of translation and transcription inhibitors on memory acquisition and retention}

Next, we examined the effect of mRNA and protein synthesis inhibitors on memory induced by massed or spaced training since LTM, but not STM/MTM requires both protein synthesis and mRNA transcription (Flood et al. 1973; Mizumori et al. 1987; Tully et al. 1994; Crow et al. 1997). Before the spaced training, worms were cultivated on agar plates spread with bacteria in the presence of $0.3 \mu \mathrm{g} / \mathrm{mL}$ of cycloheximide, $0.3 \mu \mathrm{g} / \mathrm{mL}$ of anisomycin, or $0.1 \mu \mathrm{g} / \mathrm{mL}$ of actinomycin $\mathrm{D}$ at a final concentration for $2 \mathrm{~h}$, and then during the resting intervals of the spaced training, worms were also placed on agar plates spread with bacteria that contain the drug. Therefore, worms were cultivated on agar plates containing the drug for $\sim 3.7 \mathrm{~h}$ in total. As shown in Figure $5 \mathrm{~A}$, the spaced training of the worms failed to induce the memory, indicating that both transcription and translation are required for memory formation. As shown in Figure 5B, in contrast, memory induced by the massed training required neither transcription nor translation, since the memory was normally induced in
A
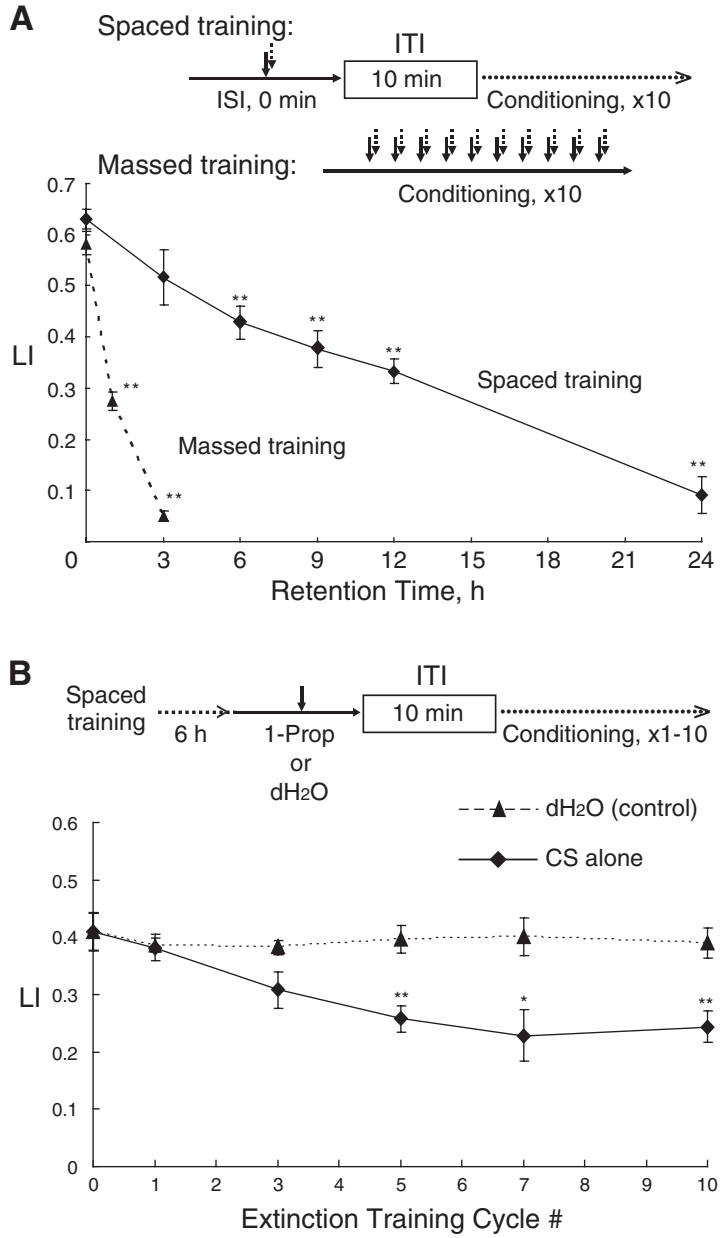

Figure 3. Memory retention and extinction learning. (A) Memory retention induced by massed or spaced training. Flowcharts of the spaced and massed training protocols used are shown at top. In the spaced training, worms were simultaneously stimulated by being immersed in a solution containing 1-propanol and $\mathrm{HCl}$. This procedure was repeated 10 times with a $10-\mathrm{min} \mathrm{ITI}$, and the $\mathrm{LI}$ of the worms was assayed $0 \mathrm{~h}$ through $24 \mathrm{~h}$ (retention intervals) after the completion of the spaced training (solid line). In the massed training, worms were simultaneously stimulated with 1-propanol and $\mathrm{HCl}$. After this conditioning was repeated 10 times without an ITI, the worms were assayed for $\mathrm{LI} 0 \mathrm{~h}, 1 \mathrm{~h}$, and $3 \mathrm{~h}$ after the completion of the massed training (broken line). Data points are means \pm SEM ( $n=9-15$ assays). Asterisks indicate statistically significant differences $\left({ }^{* *} P<0.01\right)$ determined by one-way ANOVA with TurkeyKramer's test, in comparison to the $\mathrm{LI}$ measured immediately after the trainings. (B) Extinction learning. After the spaced training 10 times simultaneously with 1-propanol and $\mathrm{HCl}$ described above in $A$, worms were transferred to NGM plates seeded with $E$. coli and were allowed to freely move and eat at $20^{\circ} \mathrm{C}$ for $6 \mathrm{~h}$. The worms were then conditioned only with the CS (solid line) in the absence of the US as described in "Extinction" of Materials and Methods. This extinction training was repeated one to 10 times as indicated on the horizontal axis. Immediately after the extinction learning, worms were tested for LI. As a control (broken line), worms were also immersed in $\mathrm{dH}_{2} \mathrm{O}$, instead of 1-propanol, at room temperature. Data points are means $\pm \operatorname{SEM}(n=9$ assays). Asterisks indicate statistically significant differences $\left({ }^{*} P<0.05\right.$; $\left.{ }^{* *} P<0.01\right)$ determined by two-sided Student's $t$-test, in comparison to $\mathrm{LI}$ values of worms after conditioning with $\mathrm{dH}_{2} \mathrm{O}$ by the same cycle number.

worms cultivated on agar plates spread with bacteria in the presence of the drug for $4 \mathrm{~h}$ before the conditioning started. The final concentrations of the drugs in agar plates were determined as the lowest concentrations that prevent the LTM formation 

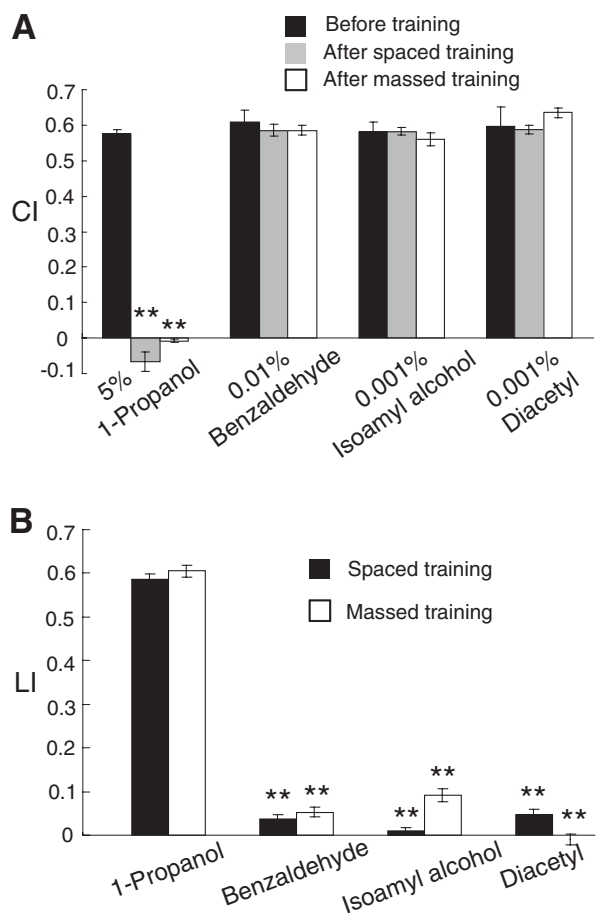

Figure 4. Propanol-specific associative learning. (A) Wild-type worms were conditioned 10 times simultaneously with 1-propanol and $\mathrm{HCl}$ by spaced (with a 10-min ITI) or massed training. Immediately after the training, worms were assayed for their ability of chemotaxis to 5\% 1-propanol, $0.01 \%$ benzaldehyde, $0.001 \%$ isoamyl alcohol, or $0.001 \%$ diacetyl spotted on the edge of chemotaxis agar plates. Note that chemotactic behaviors of the trained worms to benzaldehyde, isoamyl alcohol, and diacetyl were not affected by the training. Data are means $\pm \operatorname{SEM}(n=9$ assays). Asterisks indicate statistically significant differences $(* * P<0.01)$ determined by one-way ANOVA with Bonferroni/Dunn test, in comparison to the $\mathrm{Cl}$ of naive worms (before training). (B) Associative learning of 1-propanol with $\mathrm{HCl}$ was specific for 1-propanol. LI values were calculated from the data shown in $A$. Data are means $\pm \operatorname{SEM}(n=9$ assays). Asterisks indicate statistically significant differences $(* * P<0.01)$ determined by one-way ANOVA with Bonferroni/Dunn test, in comparison to the LI of worms assayed with 1-propanol as a stimulus.

(Supplemental Fig. S4), but did not affect worm's chemotaxis to 1-propanol (Supplemental Fig. S5). Under similar conditions used for the training in the presence of the drug, 50\% of protein synthesis was indeed inhibited by the drug treatment as shown in Supplemental Figure S6. These results indicate that the memories generated by the massed and spaced trainings are STM/MTM and LTM, respectively.

\section{Sensitivity of memory to disruption}

Before consolidation, memory is vulnerable to disruption and can be sensitive to anesthesia such as cold shock (Tully et al. 1994). Therefore, we examined whether the memory induced by the massed training, but not the memory induced by the spaced training, is sensitive to cold shock. Immediately after the massed or spaced training, worms were anesthetized by soaking them in icecold $\mathrm{dH}_{2} \mathrm{O}$ for $5.0 \mathrm{sec}$. After recovering the worms at room temperature for $5 \mathrm{~min}$ on an agar plate with bacteria, the worms were assayed for chemotaxis to 1-propanol. As shown in Figure 6, the cold shock did not affect the memory acquisition and retention induced by the spaced training, while the memory induced by the massed training was markedly erased by the cold shock.

These results indicate that the memory after the spaced training is resistant to cold shock, and is consolidated during the repetitive conditioning with a 10-min ITI. Since the memory induced by the spaced training was retained for $\sim 24 \mathrm{~h}$, required transcription and translation for its formation, and was resistant to the cold-shock anesthesia, it is therefore classified as LTM by definition. In contrast, the memory after the massed training is classified as STM/MTM, since it was no longer observable within $3 \mathrm{~h}$, required neither protein synthesis nor mRNA transcription for its acquisition, and was disrupted by the cold-shock anesthesia. Until amnesiac dependency of the memory is examined, however, it cannot be distinguished whether the memory is STM or MTM. Unfortunately, on the C. elegans genome, an ortholog of the amnesiac gene has not yet been found.

\section{C. elegans mutants defective in STM/MTM and/or LTM}

The C. elegans genome encodes "learning and memory genes," including crh-1 encoding the ubiquitous transcription-factor CREB (cAMP responsible element binding protein), glr-1 and

A A Spaced training:

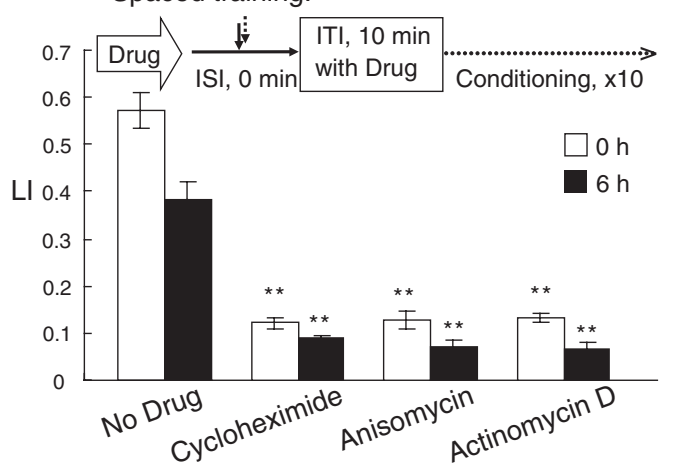

B

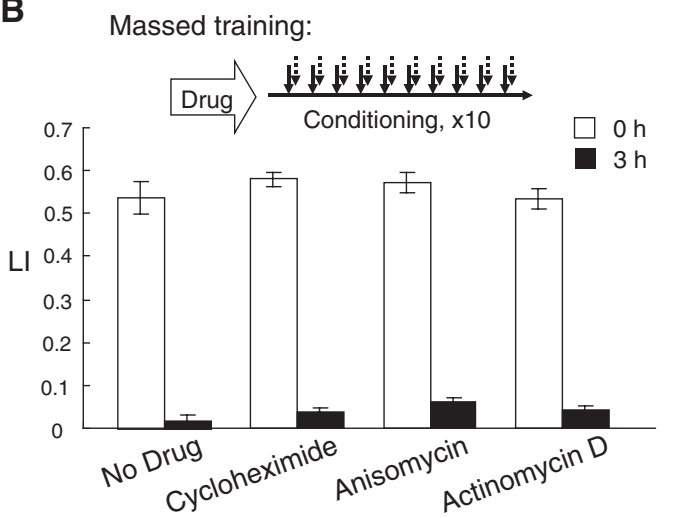

Figure 5. Effect of translation and transcription inhibitors on memory acquisition and retention. (A) A flowchart of spaced training used is shown at top. Worms were cultivated on an NGM plate spread with bacteria, which contained one of the indicated drugs for $2 \mathrm{~h}$, and trained 10 times with a 10-min ITI as shown in the flowchart. During the ITI, worms were placed on an NGM plate with a bacterial lawn, which contains the indicated drug. The worms were tested for their LI by chemotaxis assay immediately (open bars) and $6 \mathrm{~h}$ (closed bars) after the completion of the spaced training. ( $B)$ A flowchart of massed training used is shown at top. Worms were cultivated for $4 \mathrm{~h}$ on an NGM plate spread with a bacterial lawn, which contained one of the indicated drugs, and trained 10 times without an ITI. The worms were tested for their LI by chemotaxis assay immediately (open bars) and $3 \mathrm{~h}$ (closed bars) after the completion of the massed training. Data are means \pm SEM ( $n=9$ assays). Asterisks indicate statistically significant differences $\left({ }^{* *} P<0.01\right)$ determined by one-way ANOVA with the Bonferroni/Dunn test, in comparison to the LI of worms untreated with drug. 
A
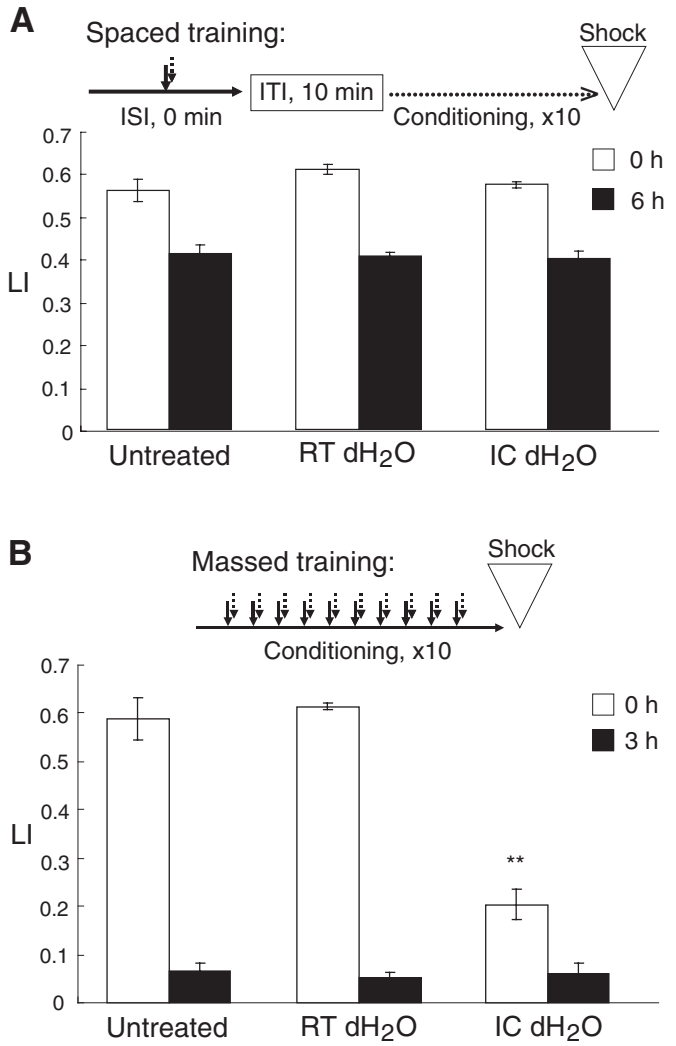

Figure 6. Sensitivity of memory to disruption. (A) A flowchart of spaced training used is shown at top. Worms were simultaneously stimulated with 1-propanol and $\mathrm{HCl}$. Immediately after repeated conditioning 10 times with a 10-min ITI, the worms were soaked in either room-temperature (RT) $\mathrm{dH}_{2} \mathrm{O}$ or ice-cold (IC) $\mathrm{dH}_{2} \mathrm{O}$, and then tested for $\mathrm{LI}$ values after being cultivated on NGM plates with a bacterial lawn at $20^{\circ} \mathrm{C}$ for $0 \mathrm{~h}$ (open bars) and $6 \mathrm{~h}$ (closed bars). (B) A flowchart of massed training used is shown at top. Worms were conditioned 10 times with a solution containing both 1-propanol and $\mathrm{HCl}$, and then soaked in either room-temperature (RT) $\mathrm{dH}_{2} \mathrm{O}$ or ice-cold (IC) $\mathrm{dH}_{2} \mathrm{O}$. Immediately (open bars) or $3 \mathrm{~h}$ (closed bars) after the treatment, the worms were tested for LI by chemotaxis assay. Data are means $\pm \operatorname{SEM}(n=9$ assays). Asterisks indicate a statistically significant difference $(* * P<0.01)$ determined by one-way ANOVA with Bonferroni/Dunn test, in comparison to the LI of worms untreated.

$n m r$-1 encoding $\alpha$-amino-3-hydroxy-5-methyl-4-isoxazolepropionic acid (AMPA)-type and $N$-methyl-D-aspartate (NMDA)type glutamate receptor subunits, respectively, and stf-1 and $s t f-2$ encoding the double-stranded RNA-binding protein Staufen isoforms. These genes have been shown to play crucial roles in classical conditioning in Aplysia, C. elegans, Drosophila, and mice (Dash et al. 1990; Morrison and van der Kooy 2001; Dubnau et al. 2003; Rose et al. 2003; Xia et al. 2005). Therefore, we also examined whether these "learning and memory genes" are involved in the generation of memory after the massed or spaced training (Fig. 7). Like the wild-type N2, all of the mutants did not show detectable defects in avoidance of $\mathrm{HCl}, \mathrm{pH} 4.0$ (Supplemental Fig. S1) or in motility after the spaced or massed training (Supplemental Table S1). However, the mutants were slightly less sensitive to 1-propanol than the wild type (Supplemental Table S2), and 1-propanol concentrations used for chemotaxis assay were therefore adjusted based on the concentrations that produce similar CI values for wild type and mutants. Nonetheless, $1.0 \%$ aqueous 1-propanol was used for the spaced and massed trainings, since higher concentrations than $1.0 \%$ affected chemotactic activity of worms to 1-propanol (Supplemental Fig. S2). As shown in Figure 7, 1.0\% aqueous 1-propanol was successfully used to condition all of the wild type and mutants, except for $n m r-1$, to induce STM/MTM at similar levels. Mutations in crh-1, glr-1, and stf- 1 and stf- 2 affected only the formation of the LTM, whereas mutants defective in $n m r-1$ failed to form both the STM/MTM and LTM. The $n m r-1$ (ak4) transgenic lines, $n m r-1(a k 4) ; i x E x 98$ and 99, which have an extrachromosomal wild-type $n m r-1$ gene, were successfully trained to form the STM/MTM and LTM at the wild-type levels by the massed and spaced trainings, respectively. Hence, all of the genes tested were required for the acquisition and retention of the LTM. In contrast, none of the genes examined, except for $n m r-1$, was essential for the STM/MTM. These results are consistent with those in Aplysia, Drosophila, and mice.

\section{Discussion}

In the present study we have developed classical conditioning protocols for the study of associative learning and memory in C. elegans. The aversive olfactory conditioning with 1-propanol and $\mathrm{HCl}$ as a CS and US, respectively, has been shown to share many of the defining features of associative learning in vertebrate
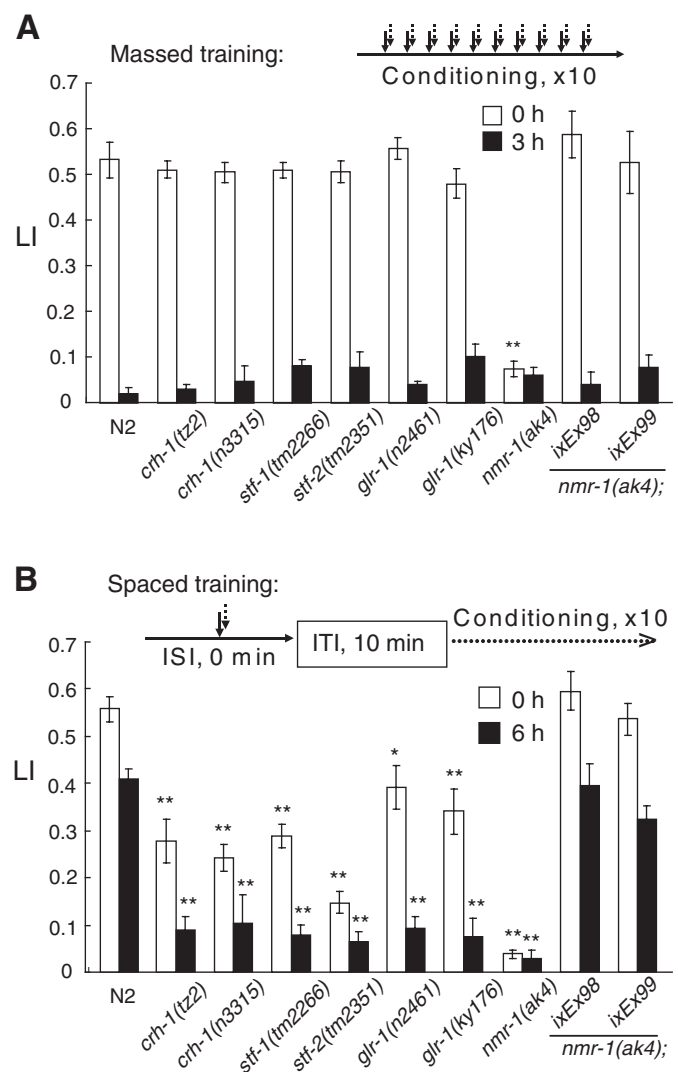

Figure 7. C. elegans mutants defective in learning and memory. (A) A massed training protocol of wild-type and mutant worms is shown at top. The worms were trained 10 times by being soaked in a solution containing both 1-propanol and $\mathrm{HCl}$, and then tested for $\mathrm{LI}$ values by chemotaxis assay immediately (open bars) and $3 \mathrm{~h}$ (closed bars) after the training. ( $B)$ A spaced training protocol used for the worms indicated is shown at top. The worms were stimulated by being soaked in a solution containing both 1-propanol and $\mathrm{HCl}$. This conditioning was repeated 10 times with a $10-\mathrm{min}$ ITI. The worms were tested for LI values by chemotaxis assay immediately (open bars) and $6 \mathrm{~h}$ (closed bars) after the training. Data are means \pm SEM ( $n=9$ assays). Asterisks indicate statistically significant differences $\left({ }^{* *} P<0.01\right)$ determined by one-way ANOVA with the Bonferroni/Dunn test, in comparison to the LI of N2 worms. 
and invertebrate species, as exemplified by classical (Pavlovian) conditioning. These include stimulus and paring specificity, contiguity learning, and both short/middle-, as well as long-term retention. Furthermore, it is also possible to extinguish the learned behavior to some extent by extinction training, in which the presentation of the reinforcing stimulus is withheld. The STM/MTM and LTM are successfully induced by the massed training and spaced training, respectively; the LTM formation is protein synthesis dependent, while STM/MTM is not. Only the difference between the two training protocols is an ITI between the trials in the spaced training. The optimal ITI length was determined to be 10 min for both acquisition and 3-h retention of the LTM (Fig. 2B). This optimal ITI length is similar to those of other organisms, including fruit flies, honeybees, and crickets (Beck et al. 2000; Menzel et al. 2001; Matsumoto and Mizunami 2002; Giurfa et al. 2009). Although the spacing effect has long been observed at the behavioral level, the underlying cellular and molecular mechanisms are poorly understood. Mitogen-activated protein kinase (MAPK) activity has been implicated in memory formation in invertebrates and vertebrates (Kandel 2001; Kelleher et al. 2004; Mayford 2007; Cammarota et al. 2008), and more recent studies suggest that MAPK activation during ITI is required for LTM (Ye et al. 2008; Pagani et al. 2009).

There are convincing examples of classical conditioning that simultaneous pairing is as effective, or more effective than forward pairing (Heth and Rescorla 1973; Mahoney and Ayres 1976; Rescorla 1980; Tully and Quinn 1985; Barnet et al. 1991, 1993; Lent and Kwon 2004). Consistent with these examples, the results described in the present study demonstrate that the most efficacious procedure for the classical conditioning inducing the LTM is to have the simultaneous onset of the CS and US, and also show that the backward pairing is as effective as the forward pairing (Fig. 2A). The closer the CS and US are together in time, the greater the LTM induced. Indeed, Lin and Glanzman (1997) have found that associative long-term synaptic changes are sensitive only to the amount of temporal contiguity between stimuli, and can mediate simultaneous, backward, and forward pairings. In contrast, there are results indicating that the most efficacious procedure for many types of classical conditioning is to have the onset of the CS precede that of the US (Maier et al. 1976; Hellstern et al. 1998; Matsumoto and Mizunami 2002). Temporal parameters that characterize different classical conditioning paradigms may result from underlying, intrinsic different mechanisms. Alternatively, all types of associative learning may be intrinsically sensitive only to the temporal correlation between stimuli, not to stimulus order. According to this view, the order specificity that characterizes some forms of classical conditioning may be due to neuronal circuits that transmit the stimuli to a critical site for associative learning.

In the present study, we have also analyzed the effects of various mutations of genes, $n m r-1$, glr-1, crh-1, stf-1, and stf-2, on the formation of STM/MTM and LTM (Fig. 7). All of the mutations except for $n m r-1$ affected only the LTM; the $n m r-1$ mutant was defective in the formation of both STM/MTM and LTM. In C. elegans, nmr-1, a homolog of NMDA receptor subunits, is expressed only in six pairs of neurons (AVA, AVD, ADE, RIM, AVG, and PVC) (Brockie et al. 2001a,b). In these neurons, the NMDA receptor may act as a molecular coincidence detector for 1-propanol and $\mathrm{HCl}$ signals in synaptic plasticity, where synaptic strengthening required for both STM/MTM and LTM can result from coincidental firing of the pre- and postsynaptic neurons (Gustafsson and Wingstrom 1988; Kauer et al. 1988; Bliss and Collingridge 1993; Bailey et al. 2000). Influx of calcium through the NMDA receptor into the postsynaptic cells can result in activation of several protein kinases including MAPK (Bailey et al. 2000; Wang et al. 2007), which may in turn phosphorylate the transcription-factor
CREB encoded by crh-1 expressed in C. elegans head neurons (Kimura et al. 2002; Suo et al. 2009). CREB is a member of the basic region/leucine zipper (bZip) family of transcription factors, which is regulated by increases in the intracellular levels of cAMP and calcium (Carlezon et al. 2005), and activates a cascade of genes that leads to LTM (Dash et al. 1990; Yin et al. 1994; Kogan et al. 1996). The stf-1 and stf-2 encode highly conserved dsRNA-binding Staufen proteins and are involved in the formation of LTM cooperatively with pumilio in Drosophila (Dubnau et al. 2003). Vertebrate Staufen localizes to dendritic sites in hippocampal neurons and are implicated in translational control at distal synaptic sites. Depletion of Staufen was found to significantly reduce both $\beta$-actin mRNA containing ribonucleoproteins and $\beta$-actin mRNA at dendritic sites, suggesting Staufen regulates the dendritic cytoskeleton (Loya et al. 2010). Also, Staufen may regulate the synthesis of glutamate receptors through microRNAs (Karr et al. 2009). glr-1, which encodes one of subtypes of ionotropic glutamate receptor channels, is critical for LTM in C. elegans, and the expression and localization altered by conditioning are necessary for the formation of long-term habituation (Rose et al. 2005). It has also been found that $g l r-1$ mutants are deficient in an olfactory associative learning task, in which diacetyl is paired with acetic acid, as well as in nonassociative learning (habituation) with the same diacetyl stimulus (Morrison and van der Kooy 2001). In this associative learning paradigm, the attractive response of naive worms to diacetyl was reduced after the conditioning, but did not completely disappear like the learned behavior seen in the present study. This may be due to the short 1.0-min ITI, and/or due to dual aversive and appetitive effects of acetic acid (Frøkjær-Jensen et al. 2008). The associative STM/MTM induced by the massed training in the present study may be different from the nonassociative learning (habituation), although it is not clear whether the nonassociative habituation is STM or not. The STM/MTM of the present study may be formed at the level of neural circuits since NMDA receptors are involved, while the nonassociative habituation may occur in the sensory neuron AWA itself.

Thus, we have found that C. elegans can learn and form associative LTM after spaced training, which is retained for $>24 \mathrm{~h}$ after the conditioning, is sensitive to inhibitors of mRNA and protein synthesis, while associative STM/MTM induced by massed training, which is no longer observable within $3 \mathrm{~h}$ after the conditioning, is resistant to the inhibitors. These are major features of LTM and STM/MTM (Tully et al. 1994; Crow et al. 1997; Epstein et al. 2003; Fulton et al. 2005). Furthermore, the associative LTM is stimulus and paring specific, depends on contiguous CS-US stimulation, and can be partially extinguished by extinction learning. During the course of the present study, Kauffman et al. (2010) have reported long-term associative memory induced by spaced training with butanone and food in C. elegans, in which cold shock efficiently erased the LTM, but not STM/MTM. This is different from our results, in which cold shock erased only the STM/MTM, but not LTM as observed in other organisms (Yamada et al. 1992; Tully et al. 1994; Tamura et al. 2003). In the cold-shock protocol by Kauffman et al. (2010), worms were placed at $-20^{\circ} \mathrm{C}$ for $15 \mathrm{~min}$, in contrast to the protocol in the present study, in which worms were placed in ice-cold water for $5.0 \mathrm{sec}$. The two different cold-shock protocols may have different effects on LTM and STM/MTM.

\section{Materials and Methods}

\section{Strains and culture media}

All strains were derived from the wild-type C. elegans variety Bristol, strain N2. Mutant strains, crh-1(tz2), glr-1(n2461), and $n m r-1(a k 4)$ used in this study were provided by the 
Caenorhabditis Genetics Center at the University of Minnesota, Minneapolis, MN. Other mutants, stf-1(tm2266) and stf2(tm2351), were obtained from National Bioresource Project for the Nematode (Tokyo Women's Medical University School of Medicine, Tokyo, Japan). $c r h-1(n 3315)$ and $g l r-1(k y 176)$ were generous gifts from Mark Alkema (University of Massachusetts School of Medicine, MA) and Andres Maricq (University of Utah, Salt Lake City, UT), respectively. The wild-type N2 and mutant strains were grown on $\mathrm{NGM}(50 \mathrm{mM} \mathrm{NaCl}, 20 \mathrm{~g} / \mathrm{L}$ of agar, $2.5 \mathrm{~g} / \mathrm{L}$ of peptone, $1.0 \mathrm{mM}$ cholesterol, $1.0 \mathrm{mM} \mathrm{CaCl} 2,1.0 \mathrm{mM} \mathrm{MgSO}_{4}$, and $25 \mathrm{mM}$ potassium phosphate at $\mathrm{pH}$ 6.0) seeded with Escherichia coli (E. coli) OP50 or NA22 to adulthood under unstarved conditions at $20^{\circ} \mathrm{C}$ using standard methods (Brenner 1974).

\section{Transgenic strains}

Transgenic lines were made using standard protocols (Mello et al. 1991). To generate $n m r-1$ rescue lines, a $13-\mathrm{kb} n m r-1$ genomic DNA fragment was amplified by PCR, using oligonucleotide primers, 5'-CACCGCGGCCGCGACAAAAGAAAACCAAATATTGTA and 5'ATCTGCAGCATGCTGAGTTCCGAATCACTGATC, and N2 genomic DNA as a template. A resulting PCR product was purified from agarose gel by using a QIAquick Gel Extraction Kit (QIAGEN), and then the purified PCR product, $10 \mathrm{ng} / \mu \mathrm{L}$, was coinjected with lin-44p::GFP (Murakami et al. 2001), $50 \mathrm{ng} / \mu \mathrm{L}$, into $n m r-1$ (ak4). Two days after DNA injection, four worms expressing GFP were allowed to self-fertilize. Two transgenic lines that express GFP at high frequencies were termed as $n m r-1(a k 4) ; i x E x 98$ [ $n m r-1 \mathrm{gDNA}$; lin-44p::GFP] and nmr-1(ak4);ixEx99[nmr-1 gDNA; lin-44p::GFP], and were used as $n m r-1(a k 4)$-rescued lines for experiments. The genotype of the transgenic lines was confirmed by PCR amplification of a portion of the gene using oligonucleotide primers, 5'-GTTCAACGTTACATTGAGGTAG and 5'-CTTCATATTCACAAG CCCAAGTCTT, and genomic DNA as a template (Supplemental Fig. S7). To prepare genomic DNA, worms suspended in lysis buffer (2.5 mM KCl, $5 \mathrm{mM}$ Tris- $\mathrm{HCl}$ at $\mathrm{pH} 8.0,0.23 \%$ Tween-20, and $200 \mu \mathrm{g} / \mathrm{mL}$ of proteinase $\mathrm{K}$ ) were incubated at $55^{\circ} \mathrm{C}$ for $4 \mathrm{~h}$. Genomic DNA was purified from the lysates by phenol/chloroform extraction, followed by ethanol precipitation.

\section{Worm preparation and chemotaxis assay}

Well-fed worms on day 4 after hatching were used to minimize the effects of age, locomotion, and olfactory sensitivity on assays. Naive worms, about 100, were removed from their NGM plates immediately before testing by washing them off with a $0.25 \%$ aqueous gelatin (WAKO Pure Chemical Industries) solution into 1.5-mL Eppendorf tubes (Eppendorf). After the tubes were allowed to stand still for $2 \mathrm{~min}$ at room temperature, worms were collected at the bottom of the tubes by removing the supernatant with a pipette or an aspirator. Likewise, the worms were washed twice with a $1.0-\mathrm{mL} 0.25 \%$ aqueous gelatin solution. The worms were then placed along a central line of chemotaxis assay plates with a blunted pipette tip, and an excess of water was removed with a piece of Kimwipes (Kimberly-Clark).

Chemotaxis assay plates were prepared by mixing $15 \mathrm{~g} / \mathrm{L}$ of Bactoagar (Becton Dickinson KK), $5 \mathrm{~mL} / \mathrm{L}$ of $1.0 \mathrm{M}$ potassium phosphate (pH 6.0$), 1.0 \mathrm{~mL} / \mathrm{L}$ of $1.0 \mathrm{M} \mathrm{CaCl}_{2}$, and $1.0 \mathrm{~mL} / \mathrm{L}$ of $1.0 \mathrm{M} \mathrm{MgSO}_{4}$. These stock solutions were sterilized by autoclaving before mixing. Agar plates were made by pouring $14 \mathrm{~mL}$ of the mixture into square plates $(10 \mathrm{~cm} \times 10 \mathrm{~cm})$ (Becton Dickinson), and then were left with lids at room temperature overnight. A total of $2 \mu \mathrm{L}$ each of $5 \%$ (unless otherwise stated) aqueous 1-propanol (WAKO) was spotted at two places along the square plate edge (Fig. 1A). The worms were allowed to move freely on the plate for $10 \mathrm{~min}$ at room temperature. Chemotaxis assay was terminated by killing the worms by placing $1.0 \mathrm{~mL}$ of chloroform on the lid. A particular CI value was calculated as (number of worms in area "a" - number of worms in area " $b$ ")/total number of worms in areas "a" and "b" (Fig. 1A). A learning index (LI) was calculated by subtracting the CI of conditioned worms $\left(\mathrm{CI}_{\text {conditioned }}\right)$ from that of reference worms $\left(\mathrm{CI}_{\text {reference }}\right)$ (Fig. 1B). The $\mathrm{CI}_{\text {reference }}$ was the mean of CI values of worms treated with the CS alone and US alone as conditioned worms. Chemotaxis assay was also carried out by using 1-propanol or isoamyl alcohol diluted with $\mathrm{dH}_{2} \mathrm{O}$, or benzaldehyde, or diacetyl diluted with ethyl alcohol as a stimulus, which was spotted along the edge of the chemotaxis assay plates. Unless otherwise stated, all of the chemotaxis assays were carried out at least in triplicate on three separate days (typically nine assays in total).

\section{Simultaneous conditioning with CS and US}

Before conditioning, worms were washed from their NGM plates directly into a worm collector that had been previously washed with $0.25 \%$ aqueous gelatin solution. Worm collectors were made from a transparent plastic pipe (3.5-cm length, 30- $\mathrm{mm}$ external diameter, 2-mm wall thickness) (Asahi Kasei) by attaching nylon mesh (30- $\mu \mathrm{m}$ mesh size) (SEFAR) to the bottom of the tube with glue (Aron Alpha/High Speed EX, Toagosei). A $\sim 50-\mathrm{mL}$ mixture of 1.0\% 1-propanol and $100 \mu \mathrm{M} \mathrm{HCl}(\mathrm{pH} 4.0)$, in a glass slide staining dish with a lid (Matsunami Glass) was used for simultaneous conditioning of worms with CS and US. A $100-\mu \mathrm{M}$ aqueous $\mathrm{HCl}$ ( $\mathrm{pH} 4.0$ ) was made by diluting concentrated $\mathrm{HCl}$ (Nacalai Tesque) with $\mathrm{dH}_{2} \mathrm{O}$, which was prepared by using Millipore Synthesis A10, immediately before use. The concentration of $\mathrm{HCl}$ as US was determined as the lowest acidic $\mathrm{pH}$ that did not affect chemotaxis of wild-type worms to 1-propanol after conditioning five times by spaced training with a 10-min ITI (Supplemental Fig. S8). The simultaneous conditioning was carried out by briefly $(<1.0 \mathrm{sec})$ dipping a worm collector with worms into a glass slide staining dish with a solution containing both 1-propanol and $\mathrm{HCl}$. Then, the worm collector was gently immersed once in $\sim 1.0 \mathrm{~L}$ of $\mathrm{dH}_{2} \mathrm{O}$ in a beaker. An excess of water in the collector was removed with a piece of Kimtowels (KimberlyClark), and then the collector with worms was placed on an NGM plate seeded with $E$. coli OP50 during an ITI for the worms to rest. This cycle of conditioning was repeated up to 10 times with various ITI lengths. After the final trial, the worms were washed with $\sim 1.0 \mathrm{~L}$ of $\mathrm{dH}_{2} \mathrm{O}$ as described above, and then suspended in a $\sim 1.0-\mathrm{mL} 0.25 \%$ aqueous gelatin solution. The worm suspension was transferred to a 1.5-mL Eppendorf tube with a blunted pipette tip, and the worms were collected to the bottom of the tube by gravity for $\sim 2 \mathrm{~min}$ at room temperature. Likewise, the worms were washed twice with $\sim 1.0 \mathrm{~mL} 0.25 \%$ aqueous gelatin solution. After the wash, the worms were placed along a central line on a chemotaxis assay plate with a blunted pipette tip, and the gelatin solution was removed with a piece of Kimwipes as much as possible.

\section{Conditioning with various ISI lengths}

Conditioning with ISI was carried out as described above in the simultaneous conditioning section, except that brief $(<1.0 \mathrm{sec}$ each) exposures to CS and US were separated by various lengths of time ranging from 0 sec to $2 \mathrm{~min}$ as an ISI. The order of stimulation with CS and US was also changed as forward (CS $\rightarrow$ US) or backward (US $\rightarrow$ CS) conditioning. After a brief $(<1.0 \mathrm{sec})$ exposure to the second stimulus, worms were briefly washed by gently immersing a worm collector in $\sim 1.0 \mathrm{~L}$ of $\mathrm{dH}_{2} \mathrm{O}$ in a beaker. After removing an excess of water with a piece of Kimtowels, the worms were placed on an NGM plate seeded with E. coli OP50 during a 10-min ITI as described above. After repeating the conditioning five times, the worms were transferred to a chemotaxis assay plate for testing as described above. All other aspects of conditioning, testing, and scoring were exactly as described above.

\section{CS-alone conditioning}

Conditioning with a CS alone, as a reference for unconditioned effects of 1-propanol, was performed as described above. A glass slide staining dish containing $\sim 50 \mathrm{~mL}$ 1-propanol diluted at a ratio of $1 / 100$ with $\mathrm{dH}_{2} \mathrm{O}$ was used for the $\mathrm{CS}$-alone conditioning. After a brief $(<1.0 \mathrm{sec})$ exposure to the CS, worms were immersed in $\mathrm{dH}_{2} \mathrm{O}$ instead of $\mathrm{HCl}$ during the conditioning. All other aspects 
of conditioning, testing, and scoring were exactly as described above.

\section{US-alone conditioning}

Conditioning with a US alone, as a reference for unconditioned effects of $\mathrm{HCl}$ ( $\mathrm{pH} 4.0$ ), was performed as described above. A glass slide staining dish containing $\sim 50 \mathrm{~mL} 100 \mu \mathrm{M} \mathrm{HCl}(\mathrm{pH} 4.0)$ was used for the US-alone conditioning. After briefly $(<1.0 \mathrm{sec})$ being immersed in $\mathrm{dH}_{2} \mathrm{O}$ instead of 1-propanol, worms were briefly $(<1.0 \mathrm{sec})$ immersed in $100 \mu \mathrm{M} \mathrm{HCl}(\mathrm{pH} 4.0)$ in a glass slide staining dish at room temperature, and were then gently washed with $\mathrm{dH}_{2} \mathrm{O}$ as describe above. All other aspects of conditioning, testing, and scoring were exactly as described above.

\section{Massed training}

Worms were conditioned with a CS and US simultaneously, with ISI, with the CS alone, or with the US alone as described above. The trial was repeated either five or 10 times without an ITI between two consecutive trials. Immediately after washing with $\mathrm{dH}_{2} \mathrm{O}$, worms were subjected to the next cycle of the trial. All other aspects of conditioning, testing, and scoring were exactly as described above.

\section{Spaced training}

Worms were conditioned as described above, except that the worms rested on an NGM plate seeded with E. coli OP50 for 10 min (unless otherwise indicated) between two consecutive trials at room temperature. The trial was repeated either five or 10 times, unless otherwise stated. All other aspects of conditioning, testing, and scoring were exactly as described above.

\section{Extinction}

After spaced training 10 times with a 10-min ITI described above, worms were transferred to NGM plates seeded with E. coli OP50, and were allowed to freely move and eat at $20^{\circ} \mathrm{C}$ for $6 \mathrm{~h}$. The worms were then washed from their NGM plates directly into a worm collector that had been previously washed with $0.25 \%$ aqueous gelatin solution, and were conditioned only with a CS. This conditioning was carried out by briefly $(<1.0 \mathrm{sec})$ dipping the worm collector with worms into a slide staining dish containing $\sim 50 \mathrm{~mL}$ of $1.0 \%$ aqueous 1-propanol. Then, the worm collector was gently immersed once in $\sim 1$. $0 \mathrm{~L}$ of $\mathrm{dH}_{2} \mathrm{O}$ in a beaker. An excess of water in the collector was removed with a piece of Kimtowels, and then the collector with worms was placed on an NGM plate seeded with $E$. coli OP50 during an ITI for the worms to rest. This conditioning only with the CS was repeated one to 10 times with a 10-min ITI. All other aspects of conditioning, testing, and scoring were exactly as described above.

\section{Drug treatment}

NGM culture media containing drug was prepared by mixing $15 \mathrm{~g} / \mathrm{L}$ of Bactoagar, $5 \mathrm{~mL} / \mathrm{L}$ of $1.0 \mathrm{M}$ potassium phosphate $(\mathrm{pH}$ 6.0), $1.0 \mathrm{~mL} / \mathrm{L}$ of $1.0 \mathrm{M} \mathrm{CaCl}_{2}$, and $1.0 \mathrm{~mL} / \mathrm{L}$ of $1.0 \mathrm{M} \mathrm{MgSO}_{4}$ with $0.3 \mu \mathrm{g} / \mathrm{mL}$ of cycloheximide $(200 \mathrm{mg} / \mathrm{mL}$ stock solution) (Sigma), $0.3 \mu \mathrm{g} / \mathrm{mL}$ of anisomycin $(10 \mathrm{mg} / \mathrm{mL}$ stock solution) (A.G. Scientific), or $0.1 \mu \mathrm{g} / \mathrm{mL}$ of actinomycin D $(10 \mathrm{mg} / \mathrm{mL}$ stock solution) (MP Biomedicals) at a final concentration. These stock solutions were sterilized by autoclaving or filtering before mixing. Agar plates were made by pouring $8 \mathrm{~mL}$ of the mixture into culture dishes (6 $\mathrm{cm}$ in diameter) (Kord-Valmark Labware), and then by being left with lids at room temperature overnight. A day before the experiments, the agar plates were spread with a concentrated E. coli OP50 paste and were left with lids at room temperature overnight. Worms were placed on the plates, and were allowed to freely move and eat at $20^{\circ} \mathrm{C}$ for $4 \mathrm{~h}$ before massed training or for $2 \mathrm{~h}$ before spaced training. During the 10-min ITI of the spaced training, the worms were also placed on plates containing the drug. All other aspects of conditioning, testing, and scoring were exactly as described above.

\section{Cold-shock anesthesia}

Immediately after massed training, worms in a collector were gently washed by immersing the collector in $\sim 1.0 \mathrm{~L}$ of $\mathrm{dH}_{2} \mathrm{O}$ in a beaker at room temperature, and then were immersed in ice-cold $\mathrm{dH}_{2} \mathrm{O}$ for $5.0 \mathrm{sec}$. An excess of water was removed from the collector with a piece of Kimtowels, and then the collector with worms was placed on an NGM plate seeded with E. coli OP50 at room temperature for $5 \mathrm{~min}$ or $3 \mathrm{~h}$. Then, the worms were gently washed by immersing the collector in $\sim 1.0 \mathrm{~L}$ of $\mathrm{dH}_{2} \mathrm{O}$ in a beaker at room temperature, and were placed on a chemotaxis assay plate for testing as described above.

Immediately after a final ITI on an NGM plate seeded with $E$. coli OP50 in spaced training, a collector with worms was gently washed by immersing the collector in $\sim 1.0 \mathrm{~L}$ of $\mathrm{dH}_{2} \mathrm{O}$ in a beaker at room temperature, and then was immersed in ice-cold $\mathrm{dH}_{2} \mathrm{O}$ for 5.0 sec. The worms were subjected to a chemotaxis assay as described above. All other aspects of conditioning, testing, and scoring were exactly as described above.

\section{Motility assay}

After massed or spaced training, worms were examined for their motility. C. elegans moves on an agar plate by making a stereotypical sine wave. The movement of the head from peak to peak of the curve (frequency) was counted as one body bend. After the training, worms in a collector were washed with $\sim 1.0 \mathrm{~L}$ of $\mathrm{dH}_{2} \mathrm{O}$ in a beaker, and then were placed in a drop of $\mathrm{dH}_{2} \mathrm{O}$ on a chemotaxis assay plate, or an NGM plate seeded with and without E. coli OP50, using a blunted pipette tip. The drop of $\mathrm{dH}_{2} \mathrm{O}$ used for the transfer of worms was adsorbed with a piece of Kimwipes. Five minutes after the transfer, the number of body bends in a 10-sec interval was sequentially counted for each of 20 worms once the worms started moving in a forward direction on the assay plate.

\section{$\mathrm{HCl}$ avoidance assay}

An $\mathrm{HCl}$ avoidance assay was carried out on a quadrant plate (10 cm in diameter) (Kord-Valmark) (Wicks et al. 2000). A pair of opposite quadrants of a plate were filled with a mixture of $15 \mathrm{~g} / \mathrm{L}$ of Bactoagar, $10 \mathrm{~mL} / \mathrm{L}$ of $5 \mathrm{M} \mathrm{NaCl}, 1.0 \mathrm{~mL} / \mathrm{L}$ of $1.0 \mathrm{M}$ $\mathrm{CaCl}_{2}$, and $1.0 \mathrm{~mL} / \mathrm{L}$ of $1.0 \mathrm{M} \mathrm{MgSO}_{4}$, with or without $1.0 \mathrm{~mL} / \mathrm{L}$ of $1.0 \mathrm{~N} \mathrm{HCl}$. The $\mathrm{pH}$ values of the agar in the presence and absence of $\mathrm{HCl}$ were 4.0 and 6.0, respectively, when measured by using a $\mathrm{pH}$ meter (Model TPX-90, Toyo Chemical Laboratories). These solutions were sterilized by either autoclaving or filtrating before mixing. Well-fed worms on day 4 after hatching were washed three times with a $0.25 \%$ aqueous gelatin solution as described above to remove bacteria, and about 100 worms were placed at the center of four quadrants. The number of worms on the four quadrants was counted in $10 \mathrm{~min}$ at room temperature. Avoidance index (AI) values were calculated by the number of worms on the quadrants without $\mathrm{HCl}$, subtracted by the number of worms on the quadrants with $\mathrm{HCl}$.

\section{Protein labeling}

To radioactively label bacterial cells as a source of food for worms, a single colony of $E$. coli NA22 was inoculated into $100 \mathrm{~mL}$ of low-sulfate minimal medium, which was made by mixing $20 \mathrm{~mL}$ of $5 \times \mathrm{M} 9$ buffer $\left(30 \mathrm{~g}\right.$ of $\mathrm{NaHPO}_{4}, 15 \mathrm{~g}$ of $\mathrm{KH}_{2} \mathrm{PO}_{4}$, and $25 \mathrm{~g}$ of $\mathrm{NaCl}$ per liter), $1.0 \mathrm{~mL}$ of $2 \mathrm{M} \mathrm{NH}_{4} \mathrm{Cl}, 0.5 \mathrm{~mL}$ of $20 \%$ glucose, $1.3 \mathrm{~mL}$ of $5 \mathrm{mM} \mathrm{MgSO}, 500 \mu \mathrm{Ci}$ of $\left[{ }^{35} \mathrm{~S}\right]$-labeled cysteine/ methionine mixture $(1175 \mathrm{Ci} / \mathrm{mmol}, 10 \mathrm{mCi} / \mathrm{mL}$ ) (American Radiolabeled Chemicals), and a $2-\mu \mathrm{g} / \mathrm{mL}$ (final concentration) unlabeled cysteine and methionine mixture (1:3 ratio) (WAKO) with distilled water as previously described (Lewis and Fleming 1995). After overnight growth at $37^{\circ} \mathrm{C}$, the bacteria were harvested by a 10 -min centrifugation at $3500 g$. The bacterial pellet was then resuspended in $45 \mathrm{~mL}$ of low-sulfate minimal medium. The resulting bacterial suspension, $1.0 \mathrm{~mL}$, was spread on the surface of NGM agar plates $(10 \mathrm{~cm}$ in diameter) containing $0.3 \mu \mathrm{g} / \mathrm{mL}$ of cycloheximide, $0.3 \mu \mathrm{g} / \mathrm{mL}$ of anisomycin, or $0.1 \mu \mathrm{g} / \mathrm{mL}$ of 
actinomycin D at a final concentration, and the plates were left overnight at room temperature.

To radioactively label worms, approximately 1000 well-fed animals on day 4 after hatching were put on an NGM agar plate with an unlabeled NA22 bacterial lawn that contained $0.3 \mu \mathrm{g} /$ $\mathrm{mL}$ of cycloheximide, $0.3 \mu \mathrm{g} / \mathrm{mL}$ of anisomycin, or $0.1 \mu \mathrm{g} / \mathrm{mL}$ of actinomycin $\mathrm{D}$ at a final concentration at $20^{\circ} \mathrm{C}$ for $2 \mathrm{~h}$. The worms were washed off with M9 buffer from the NGM plate directly into a worm collector that had been previously washed with $0.25 \%$ aqueous gelatin solution, and were then transferred to the NGM plate with radioactively labeled NA22 in the presence or absence of $0.3 \mu \mathrm{g} / \mathrm{mL}$ of cycloheximide, $0.3 \mu \mathrm{g} / \mathrm{mL}$ of anisomycin, or $0.1 \mu \mathrm{g} / \mathrm{mL}$ of actinomycin $\mathrm{D}$ at a final concentration at $20^{\circ} \mathrm{C}$ for $2 \mathrm{~h}$. The worms were washed three times with $5 \mathrm{~mL}$ $1 \times \mathrm{M} 9$ buffer without $\mathrm{MgSO}_{4}$, and were then suspended in $200 \mu \mathrm{L}$ of $1 \times \mathrm{M} 9$ buffer without $\mathrm{MgSO}_{4}$. After incubation at $20^{\circ} \mathrm{C}$ for $10 \mathrm{~min}$, the worms were sonicated five times for $5 \mathrm{sec}$ with a 1-min interval on ice in the presence of protease inhibitors (Complete, EDTA-free, Roche). Protein concentrations of the worm suspensions were measured by using a BCA protein assay kit (ThermoFisher Scientific). After adding an equal volume of $20 \%$ aqueous trichloroacetic acid (WAKO), the worm suspension was cooled at $-20^{\circ} \mathrm{C}$ for $1.0 \mathrm{~h}$. The resulting protein precipitate was collected on a glassfiber filter (GF/C, Whatman) by aspiration using a diaphragm dry vacuum pump (DTU-20, ULVAC Technologies). The filter was dried for $5 \mathrm{~min}$ by aspiration, and radioactivity of the filter was counted in a $10-\mathrm{mL}$ liquid scintillation cocktail (CLEAR-SOL II, Nacalai Tesque) with a liquid scintillation counter (LSC-6000, Hitachi Aloka Medical).

\section{Statistical analysis}

All results are expressed as means with standard errors of the means (SEM) calculated from four to 15 assays, each of which had about 100 worms. Statistical analysis of data was done by twosided Student's $t$-test for comparison between two groups or oneway ANOVA with Bonferroni/Dunn test or Tukey-Kramer's test for multiple comparisons between groups. $P \leq 0.05$ was considered statistically significant. All analyses were carried out by using Excel 2003 (Microsoft) with the add-in software Statcel2 (OMS).

\section{Acknowledgments}

We thank M. Alkema and A. Maricq for crh-1(n3315) and $g l r-1(k y 176)$ strains, respectively. We also thank our laboratory members for critically reading the manuscript. Some C. elegans strains were provided by the Caenorhabditis Genetics Center, which is funded by the NIH National Center for Research Resources (NCRR), and National Bioresource Project for the Nematode, Japan.

\section{References}

Ardiel EL, Rankin CH. 2010. An elegant mind: Learning and memory in Caenorhabditis elegans. Learn Mem 17: 191-201.

Bailey CH, Giustetto M, Huang YY, Hawkins RD, Kandel ER. 2000. Is heterosynaptic modulation essential for stabilizing Hebbian plasticity and memory? Nat Rev Neurosci 1: 11-20.

Bargmann CI. 2006. Chemosensation in C. elegans. WormBook 25: 1-29.

Bargmann CI, Horvitz HR. 1991. Chemosensory neurons with overlapping functions direct chemotaxis to multiple chemicals in C. elegans. Neuron 7: $729-742$.

Bargmann CI, Mori I. 1997. Chemotaxis and thermotaxis. In C. elegans II (ed. DL Riddle et al.), pp. 717-737. Cold Spring Harbor Laboratory Press, Cold Spring Harbor, NY.

Bargmann CI, Hartwieg E, Horvitz HR. 1993. Odorant-selective genes and neurons mediate olfaction in C. elegans. Cell 74: 515-527.

Barnet RC, Arnold HM, Miller RR. 1991. Simultaneous conditioning demonstrated in second-order conditioning: Evidence for similar associative structure in forward and simultaneous conditioning. Learn Motiv 22: 253-268.

Barnet RC, Grahame NJ, Miller RR. 1993. Temporal encoding as a determinant of blocking. J Exp Psychol Anim Behav Process 19: 327-341.

Beck CDO, Rankin CH. 1995. Heat shock disrupts long-term memory consolidation in Caenorhabditis elegans. Learn Mem 2: 161-177.
Beck CDO, Schroeder B, Davis RL. 2000. Learning performance of normal and mutant Drosophila after repeated conditioning trials with discrete stimuli. J Neurosci 20: 2944-2953.

Bliss TVP, Collingridge GL. 1993. A synaptic model of memory: Long-term potentiation in the hippocampus. Nature 361: 31-39.

Brenner S. 1974. The genetics of Caenorhabditis elegans. Genetics 77: 71-94.

Brockie PJ, Madsen DM, Zheng Y, Mellem J, Maricq AV. 2001a. Differential expression of glutamate receptor subunits in the nervous system of Caenorhabditis elegans and their regulation by the homeodomain protein UNC-42. J Neurosci 21: 1510-1522.

Brockie PJ, Mellem JE, Hills T, Madsen DM, Maricq AV. 2001b. The C. elegans glutamate receptor subunit NMR-1 is required for slow NMDA-activated currents that regulate reversal frequency during locomotion. Neuron 31: 617-630.

Cammarota M, Bevilaqua LR, Medina JH, Izquierdo I. 2008. ERK1/2 and CaMKII-mediated events in memory formation: Is 5HT regulation involved? Behav Brain Res 195: 120-128.

Carew TJ. 1996. Molecular enhancement of memory formation. Neuron 16: $5-8$.

Carew TJ, Pinsker HM, Kandel ER. 1972. Long-term habituation of a defensive withdrawal reflex in Aplysia. Science 175: 451-454.

Carew TJ, Walters ET, Kandel ER. 1981. Classical conditioning in a simple withdrawal reflex in Aplysia californica. J Neurosci 1: 1426-1437.

Carlezon WA Jr, Duman RS, Nestler EJ. 2005. The many faces of CREB. Trends Neurosci 28: 436-445.

Cepeda NJ, Pashler H, Vul E, Wixted JT, Rohrer D. 2006. Distributed practice in verbal recall tasks: A review and quantitative synthesis. Psychol Bull 132: $354-380$.

Colbert HA, Bargmann CI. 1997. Environmental signals modulate olfactory acuity, discrimination, and memory in Caenorhabditis elegans. Learn Mem 4: 179-191.

Crow T, Siddiqi V, Dash PK. 1997. Long-term enhancement but not short-term in Hermissenda is dependent upon mRNA synthesis. Neurobiol Learn Mem 68: 343-350.

Dash PK, Hochner B, Kandel ER. 1990. Injection of the cAMP-responsive element into the nucleus of Aplysia sensory neurons blocks long-term facilitation. Nature 345: 718-721.

Davis HP, Squire LR. 1984. Protein synthesis and memory: A review. Psychol Bull 96: 518-559.

de Bono M, Maricq AV. 2005. Neuronal substrates of complex behaviors in C. elegans. Annu Rev Neurosci 28: 451-501.

DeZazzo J, Tully T. 1995. Dissection of memory formation: From behavioral pharmacology to molecular genetics. Trends Neurosci 18: 212-218.

Dostalek C. 1976. Backward conditioning in man and the criteria of conditioning. Activ Nerv 18: $26-30$.

Driscoll M, Kaplan J. 1997. Mechanotransduction. In C. elegans II (ed. DL Riddle et al.), pp. 645-677. Cold Spring Harbor Laboratory Press, Cold Spring Harbor, NY.

Dubnau J, Chiang AS, Grady L, Barditch J, Gossweiler S, McNeil J, Smith P, Buldoc F, Scott R, Certa U, et al. 2003. The staufen/pumilio pathway is involved in Drosophila long-term memory. Curr Biol 13: 286-296.

Durkovic RG, Damianopoulos EN. 1986. Forward and backward classical conditioning of the flexion reflex in the spinal cat. J Neurosci 6: $2921-2925$.

Epstein HT, Child FM, Kuzirian AM, Alkon DL. 2003. Time windows for effects of protein synthesis inhibitors on Pavlovian conditioning in Hermissenda: Behavioral aspects. Neurobiol Learn Mem 79: 127-131.

Flood JF, Rosenzweig MR, Bennett EL, Orme AE. 1973. The influence of duration of protein synthesis inhibition on memory. Physiol Behav 10: $555-562$.

Folkers E, Drain P, Quinn WG. 1993. radish, a Drosophila mutant deficient in consolidated memory. Proc Natl Acad Sci 90: 8123-8127.

Frøkjær-Jensen C, Ailion M, Lockery SR. 2008. Ammonium-acetate is sensed by gustatory and olfactory neurons in Caenorhabditis elegans. PLOS ONE 3: e2467. doi: 10.1371/journal.pone.0002467.

Fulton D, Kemenes I, Andrew RJ, Benjamin PR. 2005. A single time-window for protein synthesis-dependent long-term memory formation after one-trial appetitive conditioning. Eur J Neurosci 21: 1347-1358.

Gerber B, Wustenberg D, Schutz A, Menzel R. 1998. Temporal determinants of olfactory long-term retention in honeybee classical conditioning: Nonmonotonous effects of the training trial interval. Neurobiol Learn Mem 69: 71-78.

Giurfa M, Fabre E, Flaven-Pouchon J, Groll H, Oberwallner B, Vergoz V, Roussel E, Sandoz JC. 2009. Olfactory conditioning of the sting extension reflex in honeybees: Memory dependence on trial number, interstimulus interval, intertrial interval, and protein synthesis. Learn Mem 16: 761-765.

Gray JM, Hill JJ, Bargmann CI. 2005. A circuit for navigation in Caenorhabditis elegans. Proc Natl Acad Sci 102: 3184-3191.

Gustafsson B, Wigström H. 1988. Physiological mechanisms underlying long-term potentiation. Trends Neurosci 11: 156-162. 
Hammer M, Menzel R. 1995. Learning and memory in the honeybee. J Neurosci 15: 1617-1630.

Hawkins RD, Carew TJ, Kandel ER. 1986. Effects of interstimulus interval and contingency on classical conditioning of the Aplysia siphon withdrawal reflex. J Neurosci 6: 1695-1701.

Hedgecock EM, Russell RL. 1975. Normal and mutant thermotaxis in the nematode Caenorhabditis elegans. Proc Natl Acad Sci 72: $4061-4065$.

Hellstern F, Malaka R, Hammer M. 1998. Backward inhibitory learning in honeybees: A behavioral analysis of reinforcement processing. Learn Mem 4: $429-444$.

Heth CD, Rescorla RA. 1973. Simultaneous and backward fear conditioning in the rat. J Comp Physiol Psychol 82: 434-443.

Ishihara T, Iino Y, Mohri A, Mori I, Gengyo-Ando K, Mitani S, Katsura I. 2002. HEN-1, a secretory protein with an LDL receptor motif, regulates sensory integration and learning in Caenorhabditis elegans. Cell 109: $639-649$.

Jones JE. 1962. Contiguity and reinforcement in relation to CS-UCS intervals in classical aversive conditioning. Psychol Rev 69: $176-186$.

Kandel ER. 1976. Cellular basis of behavior. An introduction to behavioral neurobiology. W.H. Freeman and Co., San Francisco, CA.

Kandel ER. 2001. The molecular biology of memory storage: A dialogue between genes and synapses. Science 294: 1030-1038.

Karr J, Vagin V, Chen K, Ganesan S, Olenkina O, Gvozdev V, Featherstone DE. 2009. Regulation of glutamate receptor subunit availability by microRNAs. J Cell Biol 185: 685-697.

Kauer JA, Malenka RC, Nicoll RA. 1988. A persistent postsynaptic modification mediates long-term potentiation in hippocampus. Neuron 10: $911-917$.

Kauffman AL, Ashraf JM, Corces-Zimmerman MR, Landis JN, Murphy CT. 2010. Insulin signaling and dietary restriction differentially influence the decline of learning and memory with age. PLoS Biol 8: e1000372. doi: 10.1371 /journal.pbio.1000372.

Kelleher RJ 3rd, Govindarajan A, Jung HY, Kang H, Tonegawa S. 2004. Translational control by MAPK signaling in long-term synaptic plasticity and memory. Cell 116: 467-479.

Kimura Y, Corcoran EE, Eto K, Gengyo-Ando K, Muramatsu MA, Kobayashi R, Freedman JH, Mitani S, Hagiwara M, Means AR, et al. 2002. A CaMK cascade activates CRE-mediated transcription in neurons of Caenorhabditis elegans. EMBO Rep 3: 962-966.

Kogan JH, Frankland PW, Blendy JA, Coblentz J, Marowitz Z, Schutz G, Silva AJ. 1996. Spaced training induces normal long-term memory in CREB mutant mice. Curr Biol 7: 1-11.

Lent DD, Kwon H-W. 2004. Antennal movements reveal associative learning in the American cockroach Periplaneta americana. J Exp Biol 207: $369-375$.

Lewis JA, Fleming JT. 1995. Basic culture methods. In Caenorhabditis elegans: Modern biological analysis of an organism (ed. HF Epstein, DC Shakes), pp. 3-29. Academic Press, San Diego, CA.

Lin XY, Glanzman DL. 1997. Effect of interstimulus interval on pairing-induced LTP of Aplysia sensorimotor synapses in cell culture. J Neurophysiol 77: 667-674.

Loya CM, Van Vactor D, Fulga TA. 2010. Understanding neuronal connectivity through the post-transcriptional toolkit. Genes Dev 24: $625-635$.

Mahoney WJ, Ayres JJB. 1976. One-trial simultaneous and backward fear conditioning as reflected in conditioned suppression of licking in rats. Anim Learn Behav 4: 357-362.

Maier SF, Rapaport P, Wheatley KL. 1976. Conditioned inhibition and the UCS-CS interval. Anim Learn Behav 4: 217-220.

Matsumoto Y, Mizunami M. 2002. Temporal determinants of long-term retention of olfactory memory in the cricket Gryllus bimaculatus. J Exp Biol 205: 1429-1437.

Mayford M. 2007. Protein kinase signaling in synaptic plasticity and memory. Curr Opin Neurobiol 17: 313-317.

Mello CC, Kramer JM, Stinchcomb D, Ambros V. 1991. Efficient gene transfer in C. elegans: Extrachromosomal maintenance and integration of transforming sequences. EMBO J 10: 3959-3970.

Menzel R, Manz G, Menzel R, Greggers U. 2001. Massed and spaced learning in honeybees: The role of CS, US, the intertrial interval, and the test interval. Learn Mem 8: 198-208.

Mizumori SJ, Channon V, Rosenzweig MR, Bennett EL. 1987. Anisomycin impairs long-term working memory in a delayed alternation task. Behav Neural Biol 47: 1-6.

Mohri A, Kodama E, Kimura KD, Koike M, Mizuno T, Mori I. 2005. Genetic control of temperature preference in the nematode Caenorhabditis elegans. Genetics 169: 1437-1450.

Morrison GE, van der Kooy D. 2001. A mutation in the AMPA-type glutamate receptor, $g l r-1$, blocks olfactory associative and nonassociative learning in Caenorhabditis elegans. Behav Neurosci 115: $640-649$.
Morrison GE, Wen JYM, Runciman S, van der Kooy D. 1999. Olfactory associative learning in Caenorhabditis elegans is impaired in lrn-1 and lrn-2 mutants. Behav Neurosci 113: 358-367.

Murakami M, Koga M, Ohshima Y. 2001. DAF-7/TGF- $\beta$ expression required for the normal larval development in C. elegans is controlled by a presumed guanylyl cyclase DAF-11. Mech Dev 109: 27-35.

Nuttley WM, Atkinson-Leadbeater KP, van der Kooy D. 2002. Serotonin mediates food-odor associative learning in the nematode Caenorhabditis elegans. Proc Natl Acad Sci 99: 12449-12454.

Pagani MR, Oishi K, Gelb BD, Zhong Y. 2009. The phosphatase SHP2 regulates the spacing effect for long-term memory induction. Cell 139: 186-198.

Qin H, Dubnau J. 2010. Genetic disruptions of Drosophila Pavlovian learning leave extinction learning intact. Genes Brain Behav 9: 203-212.

Rankin CH. 2000. Context conditioning in habituation in the nematode Caenorhabditis elegans. Behav Neurosci 114: 496-505.

Rankin CH, Broster BS. 1992. Factors affecting habituation and recovery from habituation in the nematode Caenorhabditis elegans. Behav Neurosci 106: 239-249.

Rankin CH, Beck CD, Chiba CM. 1990. Ceanorhabditis elegans: A new model system for the study of learning and memory. Behav Brain Res 37: 89-92.

Rescorla RA. 1980. Simultaneous and successive associations in sensory preconditioning. J Exp Psycho Anim Behav Process 6: 207-216.

Riddle DL, Albert PS. 1997. Genetic and environmental regulation of dauer larva development. In C. elegans II (ed. DL Riddle et al.), pp. 739-768. Cold Spring Harbor Laboratory Press, Cold Spring Harbor, NY

Rose JK, Rankin CH. 2006. Blocking memory reconsolidation reverses memory-associated changes in glutamate receptor expression. $J$ Neurosci 26: $11582-11587$.

Rose JK, Kaun KR, Rankin CH. 2002. A new group-training procedure for habituation demonstrates that presynaptic glutamate release contributes to long-term memory in Caenorhabditis elegans. Learn Mem 9: 130-137.

Rose JK, Kaun KR, Chen SH, Rankin CH. 2003. GLR-1, a non-NMDA glutamate receptor homolog, is critical for long-term memory in Caenorhabditis elegans. J Neurosci 23: 9595-9599.

Rose JK, Sangha S, Rai S, Norman KR, Rankin CH. 2005. Decreased sensory stimulation reduces behavioral responding, retards development, and alters neuronal connectivity in Caenorhabditis elegans. J Neurosci 25: $7159-7168$.

Saeki S, Yamamoto M, Iino Y. 2001. Plasticity of chemotaxis revealed by paired presentation of a chemoattractant and starvation in the nematode Caenorhabditis elegans. I Exp Biol 204: 1757-1764.

Sambongi Y, Takeda K, Wakabayashi T, Ueda I, Wada Y, Futai M. 2000. Caenorhabditis elegans senses protons through amphid chemosensory neurons: Proton signals elicit avoidance behavior. Neuroreport 11: 2229-2232.

Schneiderman N, Gormezano I. 1964. Conditioning of the nictitating membrane of the rabbit as a function of CS-US interval. J Comp Physiol Psychol 57: 188-195.

Spetch ML, Wilkie DM, Pinel JP. 1981. Backward conditioning: A re-evaluation of the empirical evidence. Psychol Bull 89: 163-175.

Suo S, Culotti JG, Van Tol HHM. 2009. Dopamine counteracts octopamine signalling in a neural circuit mediating food response in C. elegans. EMBO J 28: 2437-2448

Tamura T, Chiang AS, Ito N, Liu HP, Horiuchi J, Tully T, Saitoe M. 2003. Aging specifically impairs amnesiac-dependent memory in Drosophila. Neuron 40: $1003-1011$

Tomioka M, Adachi T, Suzuki H, Kunitomo H, Schafer WR, Iino Y. 2006. The insulin/PI 3-kinase pathway regulates salt chemotaxis learning in Caenorhabditis elegans. Neuron 51: 613-625.

Torayama I, Ishihara T, Katsura I. 2007. Caenorhabditis elegans integrates the signals of butanone and food to enhance chemotaxis to butanone. I Neurosci 27: 741-750.

Tully T, Quinn WG. 1985. Classical conditioning and retention in normal and mutant Drosophila melanogaster. J Comp Physiol A 157: 263-277.

Tully T, Preat T, Boynton SC, Del Vecchio M. 1994. Genetic dissection of consolidated memory in Drosophila. Cell 79: 35-47.

Wang JQ, Fibuch EE, Mao L. 2007. Regulation of mitogen-activated protein kinases by glutamate receptors. J Neurochem 100: 1-11.

Ward S. 1973. Chemotaxis by the nematode Caenorhabditis elegans: Identification of attractants and analysis of the response by use of mutants. Proc Natl Acad Sci 70: 817-821.

Ward S, Thomson N, White JG, Brenner S. 1975. Electron microscopical reconstruction of the anterior sensory anatomy of the nematode Caenorhabditis elegans. J Comp Neurol 160: 313-337.

Ware RW, Clark D, Crossland K, Russell RL. 1975. The nerve ring of the nematode Caenorhabditis elegans: Sensory input and motor output. J Comp Neurol 162: 71-110.

Wen JYM, Kumar N, Morrison G, Rambaldini G, Runciman S, Rousseau J, van der Kooy D. 1997. Mutations that prevent associative learning in C. elegans. Behav Neurosci 111: 354-368. 
White JG, Southgate E, Thomson JN, Brenner S. 1986. The structure of the nervous system of the nematode Caenorhabditis elegans. Phil Trans $R$ Soc Lond B 314: $1-340$.

Wicks SR, de Vries CJ, van Luenen HGAM, Plasterk RHA. 2000. CHE-3, a cytosolic dynein heavy chain, is required for sensory cilia structure and function in Caenorhabditis elegans. Dev Biol 221: 295-307.

Xia S, Miyashita T, Fu TF, Lin WY, Wu CL, Pyzocha L, Lin IR, Saitoe M, Tully T, Chiang AS. 2005. NMDA receptors mediate olfactory learning and memory in Drosophila. Curr Biol 15: 603-615.

Yamada A, Sekiguchi T, Suzuki H, Mizukami A. 1992. Behavioral analysis of internal memory states using cooling-induced retrograde amnesia in Limax flavus. J Neurosci 12: 729-735.
Ye X, Shobe JL, Sharma SK, Marina A, Carew TJ. 2008. Small G proteins exhibit pattern sensitivity in MAPK activation during the induction of memory and synaptic facilitation in Aplysia. Proc Natl Acad Sci 105: 20511-20516.

Yin JCP, Wallach JS, Del Vecchio M, Wilder EL, Zhou H, Quinn WG, Tully T. 1994. Induction of a dominant negative CREB transgene specifically blocks long-term memory in Drosophila. Cell 79: 49-58.

Zhang Y, Lu H, Bargmann CI. 2005. Pathogenic bacteria induce aversive olfactory learning in Caenorhabditis elegans. Nature 438: 179-184.

Received March 26, 2011; accepted in revised form August 3, 2011. 


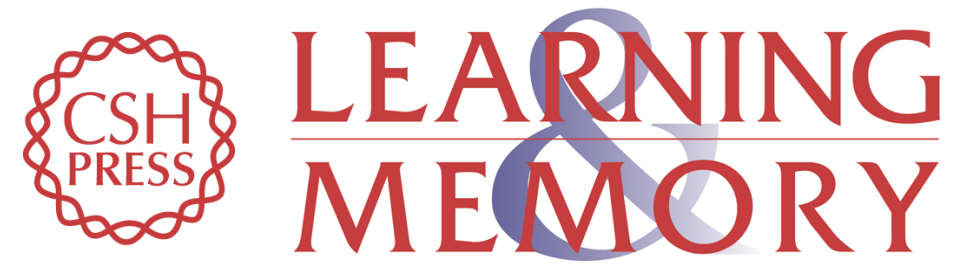

\section{Aversive olfactory learning and associative long-term memory in Caenorhabditis elegans}

Hisayuki Amano and Ichiro N. Maruyama

Learn. Mem. 2011, 18:

Access the most recent version at doi:10.1101/lm.2224411

Supplemental
Material http://learnmem.cshlp.org/content/suppl/2011/09/29/18.10.654.DC1

References This article cites 98 articles, 32 of which can be accessed free at: http://learnmem.cshlp.org/content/18/10/654.full.html\#ref-list-1

License

Email Alerting Receive free email alerts when new articles cite this article - sign up in the box at the Service top right corner of the article or click here. 